\title{
ATTITUDE AND ACCEPTANCE OF COVID-19 VACCINE AMONGST MEDICAL AND DENTAL FRATERNITY - A QUESTIONNAIRE SURVEY
}

\author{
Avineet Kaurl, Gagandeep Kaur², Akanksha Kashyap 3 , Gaganpreet Singh ${ }^{4}$, \\ Harnoor Singh Sandhu ${ }^{5}$, Iqra Khilji ${ }^{6}$, Ramandeep Singh Gambhir ${ }^{7}$
}

\author{
${ }^{1}$ Department of Periodontology and Oral Implantology, Swami Devi Dyal Dental College and Hospital, \\ Haryana, India \\ ${ }^{2}$ Dental Assistant, Charolais Dentistry, Brampton, Canada \\ ${ }^{3}$ Department of Periodontology, Babu Banarasi Das College of Dental Sciences, Lucknow, Uttar Pradesh \\ ${ }^{4}$ Civil Hospital, Jalandhar, Punjab, India \\ ${ }^{5}$ Department of Emergency, Gian Sagar Medical College and Hospital, Punjab, India \\ ${ }^{6}$ Hazrat Haleema Maternity and General Hospital, Malerkotla, Punjab, India \\ ${ }^{7}$ Department of Public Health Dentistry, Rayat and Bahra Dental College and Hospital, Mohali, India
}

\begin{abstract}
Background. The second wave of Novel Coronavirus disease (COVID-19, SARS-CoV-2) is proving more disastrous than the first because of the new mutant stains. Under these circumstances, vaccination is the only effective solution that can save millions of lives across the globe.

Objectives. The present study was conducted to assess the attitude and acceptance/willingness of health care professionals (medical and dental) towards COVID-19 vaccine.

Materials and Methods. An online questionnaire survey was conducted among medical and dental professionals working in different hospitals of two states of India. A total of 520 subjects constituted the final sample size. A self-constructed questionnaire (divided into 2 parts) containing 12 questions was administered to obtain information from the subjects regarding their attitude and willingness towards COVID 19 vaccine. Statistical analysis was done using chi-square test and multiple liner regression analysis. Odds ratio with 95\% CI were also generated. Statistical significance was set at $\mathrm{p} \leq 0.05$.

Results. Majority of the subjects (67\% of dental and $73 \%$ of medical) had full confidence on the effectiveness of COVID-19 vaccine. Willingness to get vaccinated was shown by $63 \%$ of subjects and $65 \%$ had positive attitude towards vaccine. Some subjects $(45.5 \%$ dental and $48.4 \%$ medical) showed concern regarding unforeseen effects of the vaccine. Willingness to get vaccinated was 3.45 higher in subjects who were involved in COVID duties. Subjects giving less preference to natural immunity over vaccine showed more willingness (OR: 2.98) towards getting the vaccine.

Conclusion. The findings of the study showed that acceptance and attitude of subjects regarding COVID 19 vaccine was suboptimal as there were various factors which contributed towards subjects' hesitancy to get vaccinated. There is an utmost need to address various issues regarding vaccine safety to promote high uptake.
\end{abstract}

Key words: COVID-19, safety, emergencies, health, vaccines

\section{INTRODUCTION}

In December 2019, the Novel Coronavirus disease (COVID-19, SARS-CoV-2) emerged from China, Wuhan, and is currently claiming thousands of lives everyday across the globe. Its RNA structure resembles that of the SARS-CoV-1 that triggered the Severe Acute Respiratory Syndrome (SARS) epidemic [7, 24]. World Health Organization (WHO) on March 12, 2020 classified COVID-19 as a pandemic [24]. Currently, there are 141 million active cases and 3.01 million deaths have been reported globally. India has reported the $2^{\text {nd }}$ maximum number of cases of COVID-19 with 15.6 million active cases and 1,83,000 deaths [21].

Self-quarantine and social distancing are effective measures that can decrease the Novel Coronavirus disease spread. Development of herd immunity among certain populations might have contributed towards lower morbidity [15]. However, widespread vaccination is the most active way of monitoring and lowering infectious diseases [17]. While immunization

Corresponding author: Ramandeep Singh Gambhir, Department of Public Health Dentistry, Rayat and Bahra Dental College and Hospital, Mohali, Punjab, India. PIN- 140103, Tel- +91-99156-46007, e-mail: raman2g@yahoo.com

(C) Copyright by the National Institute of Public Health - National Institute of Hygiene 
has effectively lessened the universal problem of morbidity and mortality, public assurance regarding vaccines is being exaggerated by numerous factors [8].

Maintaining assurance regarding the vaccine is subject to the interface between providers and patients $[13,14]$. Application and attitude of vaccination by healthcare authorities is a main concern that is dependably related with adherence to vaccination schedules, patient acceptance and vaccination which decreases aversion/reluctance [19]. Furthermore, vaccinated health professionals (medical and dental practitioners) have a perceptible aftereffect on patients' acceptance towards taking a vaccine.

Health authorities' tenacity to utilize and approve the vaccine to their patients can be predisposed by attitudes and knowledge concerning vaccines. It is documented that healthcare specialists who have negative attitude, hatred or reluctance concerning vaccinations, convey these approaches towards vaccination to patients which inclines them to adopt a negative towards the vaccine [2]. Moreover, vaccine doubtfulness detected in the widespread public has been associated with the level of vaccine uncertainty among health care professionals [1]. Public assurance in vaccines universally should be the primary goal for public health authorities for maximum vaccination coverage [5].

The development of an effective vaccine against COVID-19 has been a challenging task for vaccine makers worldwide. Many companies are still developing COVID-19 vaccines and many are in the final stages of trial whereas others have already completed this phase. India has already rolled out two vaccines- 'Covishield' (ChAdOx1, Oxford-Astra Zeneca vaccine) (January 2021) advanced in the UK and manufactured by Serum Institute of India's (SII)) has second one is 'Covaxin' (March 2021) which is developed by Bharat Biotech Pharma company, India [20]. First preference for vaccination is being given to front line workers and engaging in COVID 19 duties and next priority is given to all health care workers.

The caliber, content and distribution of educational data about vaccines by healthcare professionals are valuable in educating patients into accepting vaccinations [16]. Moreover, health care workers are directly exposed to the disease because in their working environment. Therefore, the objective of this questionnaire survey was to assess the attitude and willingness to accept the COVID-19 vaccine amongst medical and dental health professionals.

\section{MATERIALS AND METHOD}

\section{Ethical clearance}

Ethical clearance to conduct the present study was obtained from concerned health authorities.
Participation in the study was voluntary and informed consent was obtained from those study subjects who were willing to participate. Moreover, any type of information disclosing the identity of the patient was not collected. The study was conducted in January 2021.

\section{Study population and study sample}

The present questionnaire based study was conducted among dental and medical professionals working in different hospitals of two states in India (Punjab \& Uttar Pradesh). The following formula was used to calculate the required sample size:

$$
\mathrm{n}=\frac{\mathrm{Z}^{2} 1-(\alpha / 2) \times \mathrm{S} 2}{\mathrm{~d} 2}
$$

where: $\mathrm{Z}$ is the standard normal score with $95 \%$ confidence interval (CI) $(\alpha=0.05), S$ is the standard deviation of the variable, and $d$ is maximum acceptable error. After applying the formula, 520 subjects constituted the final sample size after excluding the non-responders. Subjects from both the medical and dental specialties were enrolled in the study using systematic random sampling methodology.

\section{Questionnaire/Research Instrument}

A self-designed close-ended questionnaire written in English was constructed specifically for the study. The content of the questionnaire was verified by infectious and communicable disease specialist and it was pre-tested for validity and reliability. The reliability of the questionnaire was good (0.82). The questionnaire was split into two sections- A 'General Section' (Section A) which was made to collect socio-demographic details of the subjects (gender, occupation, experience, working profile etc.). Section B comprised of 12 questions on knowledge, attitude and willingness regarding COVID-19 vaccine. The questionnaire was made available to study subjects via email and WhatsApp (Social Media Application) and not handed over personally in order to minimize any contact with the subjects to prevent the spread of the virus. The subjects were given one week time to fill the questionnaire and return it. The response of subjects' (positive or negative) towards the questionnaire was assessed for attitude and willingness towards the vaccine.

\section{Statistical Analysis}

Data obtained from responses to the questionnaire was assessed using SPSS statistical package (SPSS, version 21.0, Chicago, IL, USA). Categorical measurements were done using number and percentages. Chi-square test as used to examine association between different variables. The significance level was set at $<0.05$. Multivariate 
logistic regression analysis was also performed to assess the effect of various independent variables on willingness to get vaccinated. Odds ratio with $95 \% \mathrm{CI}$ were also generated.

\section{RESULTS}

\section{Socio-demographic characteristics}

The analysis of the general demographic data (Table 1) revealed that the age of the subjects ranged from 24-55 years and majority of the study subjects were in the age-group of $25-35$ years $(208,40 \%)$ and 65.6 $\%$ (340) were males. The study population comprised more of dental professionals (54.4\%) as compared to medical health professionals (45.6\%). Subjects having experience of more than 10 years were comparatively less $(41.6 \%)$ as compared to subjects having more than 10 years' experience $(58.4 \%)$. Of the total subjects, $35 \%$ (182) were doing COVID related duties at their respective workplace.

\section{Response to the questionnaire on attitude regarding the vaccine}

The responses of the subjects pertaining to attitude regarding vaccine are summarized in Figure 1. More than $85 \%$ of subjects were aware regarding the availability of COVID-19 vaccine in India by January end. Majority of the subjects $(67 \%$ of dental and $73 \%$

Table 1. Socio-demographic characteristics of the study population

\begin{tabular}{|c|c|c|c|}
\hline \multirow{2}{*}{ Socio-demographic characteristic } & Number & Percentage (\%) \\
\hline \multirow{3}{*}{ Age (in years) } & $25-35$ & 208 & 40 \\
\cline { 2 - 4 } & $35-45$ & 171 & 33.1 \\
\cline { 2 - 4 } & $45-55$ & 141 & 26.9 \\
\hline \multirow{2}{*}{ Gender } & Male & 340 & 65.6 \\
\cline { 2 - 4 } & Female & 180 & 34.4 \\
\hline \multirow{2}{*}{ Type of health care worker } & Medical & 237 & 45.6 \\
\hline \multirow{2}{*}{ Years of Experience } & Dental & 283 & 54.4 \\
\cline { 2 - 4 } & 10 & 303 & 58.4 \\
\hline \multirow{2}{*}{ Working Profile } & More than 10 & 217 & 41.6 \\
\cline { 2 - 4 } & Governmental sector & 192 & 37 \\
\hline \multirow{2}{*}{ Involved in Covid-19 duty } & Private sector & 328 & 63 \\
\cline { 2 - 4 } & Yes & 182 & 35 \\
\hline
\end{tabular}

Vaccine must for front line workers

Taking precautions even after...

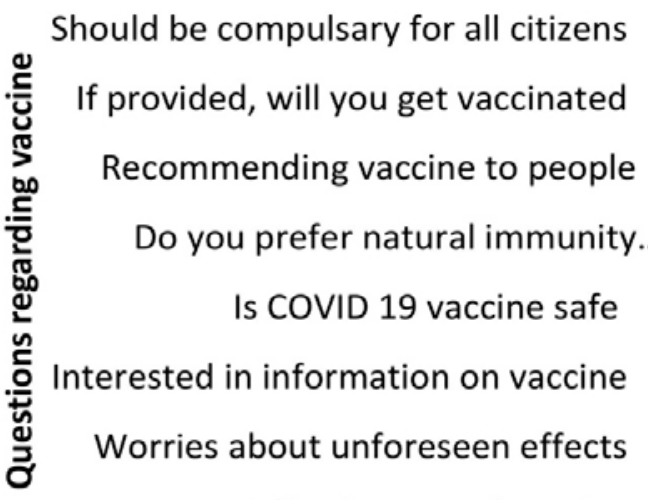

Effectiveness of vaccine

Availability of COVID-19 vaccine in...

Awareness regarding development...

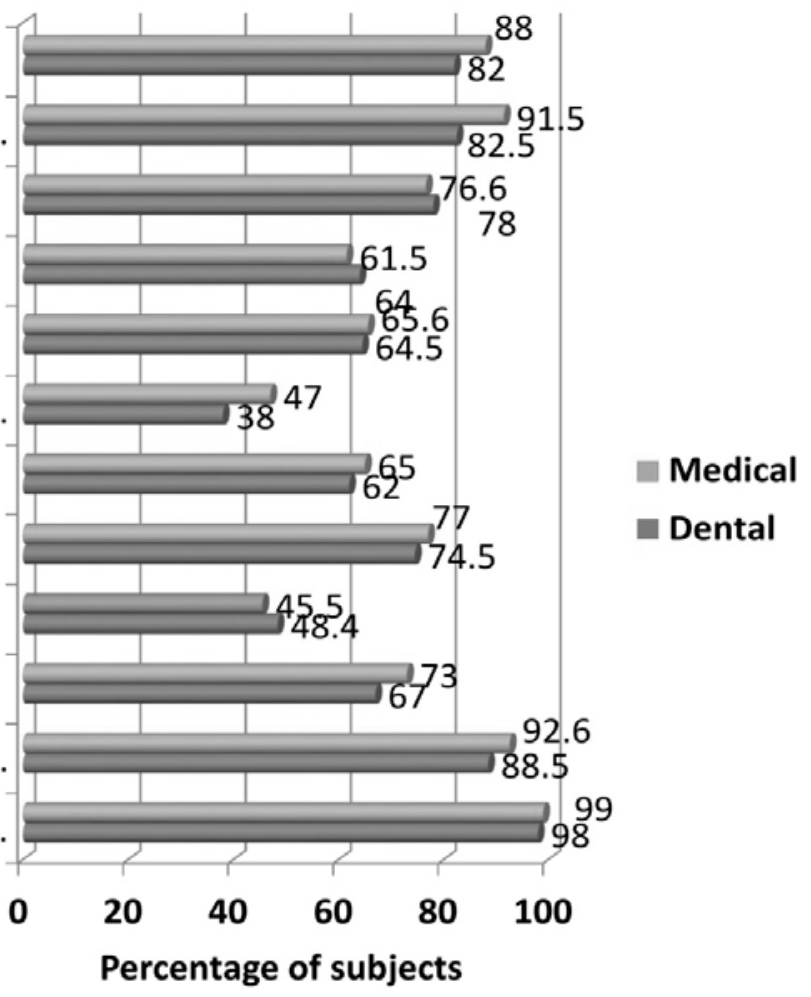

Figure 1. Subjects' response towards the questionnaire assessing attitude and willingness 
of medical) had full confidence on the effectiveness of COVID-19 vaccine and more than $60 \%$ of subjects were of the opinion that it is safe. However, some of the subjects $(45.5 \%$ dental and $48.4 \%$ medical) showed concern regarding unforeseen effects of the vaccine. More than $40 \%$ of the subjects preferred natural immunity over vaccines. When asked about their willingness to get vaccinated, $63 \%$ of subjects gave a positive response and $65 \%$ reported that they would recommend vaccine to others. Vaccine should be compulsory for all citizens of India were emphasized by $76.6 \%$ of medical and $78 \%$ of dental professionals. Overall, $65 \%$ of subjects (338) showed a positive attitude towards vaccination and the findings were significantly associated with the working profile of study subjects $(\mathrm{p}=0.024)$ (Table 2$)$.

Table 2. Attitude towards Covid-19 vaccine

\section{Multivariate logistic regression analysis}

Multivariate logistic regression analysis was also performed to assess the effect of various independent variables on the willingness of subjects to get vaccinated (Table 3). Odds ratio with $95 \%$ CI were also generated. The odds of willingness to get vaccinated were 2.12 times greater in dental health professionals as compared to medical health professionals. Willingness to get vaccinated was 3.45 higher in subjects who were involved in COVID duties as well. Subjects giving less preference to natural immunity over vaccine showed more willingness ( 2.98 times) towards getting the vaccine. Odds of getting vaccinated were 2.78 times higher among those who were interested in gathering information about the vaccine. Moreover, subjects having perception that the vaccine should be

\begin{tabular}{|c|c|c|c|}
\hline Attitude & Profile of subjects & No. (\%) & p value \\
\hline \multirow{2}{*}{ Positive } & Medical & $158(66.7 \%)$ & \multirow{2}{*}{$0.024^{*}$} \\
\cline { 2 - 3 } & Dental & $180(63.6 \%)$ & \multirow{2}{*}{0.065} \\
\cline { 2 - 3 } & Medical & $79(33.4 \%)$ & $0.065)$ \\
\hline \multirow{2}{*}{ Negative } & Dental & $123(36.3 \%)$ & \\
\cline { 2 - 3 } & &
\end{tabular}

${ }^{*}$ Chi-square test, $\mathrm{p} \leq 0.05$ Statistically significant

Table 3. Multivariate logistic regression analysis on willingness to get vaccinated

\begin{tabular}{|c|c|c|c|}
\hline Variable & OR (Odds Ratio) & $95 \% \mathrm{CI}$ & $\mathrm{p}$ value \\
\hline \multicolumn{4}{|c|}{ Type of health worker } \\
\hline Medical & 1.00 & $0.54-3.56$ & $0.023^{*}$ \\
\hline Dental & 2.12 & & \\
\hline \multicolumn{4}{|c|}{ Years of experience } \\
\hline 10 & 1.00 & $1.00-3.76$ & 0.065 \\
\hline More than 10 & 2.65 & & \\
\hline \multicolumn{4}{|c|}{ Working profile } \\
\hline Government sector & 1.32 & $0.67-2.87$ & 0.071 \\
\hline Private sector & 1.00 & & \\
\hline \multicolumn{4}{|c|}{ Involved in COVID duties } \\
\hline Yes & 3.45 & $1.2-5.61$ & $0.002 *$ \\
\hline No & 1.00 & & \\
\hline \multicolumn{4}{|c|}{ Do you prefer natural immunity over vaccine } \\
\hline Yes & 1.00 & $0.5-4.34$ & $0.034^{*}$ \\
\hline No & 2.98 & & \\
\hline \multicolumn{4}{|c|}{ Is COVID 19 Vaccine safe } \\
\hline Yes & 2.46 & $0.72-3.78$ & $0.045^{*}$ \\
\hline No & 1.00 & & \\
\hline \multicolumn{4}{|c|}{ Interested in information on vaccine } \\
\hline Yes & 2.78 & $1.45-3.23$ & $0.045^{*}$ \\
\hline No & 1.00 & & \\
\hline \multicolumn{4}{|c|}{ Vaccine should be compulsory for all Indian citizens } \\
\hline Yes & 3.23 & $1.06-3.78$ & $0.027^{*}$ \\
\hline No & 1.00 & & \\
\hline
\end{tabular}

${ }^{*} \mathrm{p} \leq 0.05$, statistically significant 
compulsory for all Indian citizens were more willing to get vaccinated (OR: 3.23$)$.

\section{DISCUSSION}

High rates of vaccination against diseases in a population have been one of the most important advances for maintenance of public health around the globe. Since the start of the current pandemic, scientists all over the world have been working tirelessly to develop new and effective vaccines that can guard people from COVID-19 and its new variants [12]. More than 100 vaccine candidates are being developed world widely by different pharmaceutical companies. Some of the companies have already introduced their vaccines while others are in their last stages of clinical trials. Recent evidence suggests that people who are fully vaccinated for COVID-19 are less likely to be infected without showing symptoms and therefore are less likely to spread infection to others [3].

Although more than $95 \%$ of subjects were aware regarding the development of vaccine against COVID-19, more than one-third of subjects (37\%) were unwilling to get vaccinated. This acceptance rate is lower as compared to some study conducted in another part of the world [6] but high as compared to a recent study conducted among health care workers in Saudi Arabia [18]. A possible explanation for this could be due to concerns regarding possible substandard vaccine quality and misinformation conveyed by certain social and mass media sources which have spread rumors regarding the safety of COVID-19 vaccine in people belonging to some race/ ethnicity [4]. Vaccine hesitancy developed among medical and dental practitioners can impact their own decision to get vaccinated and to endorse the vaccine to their patients. Social media influencers and celebrities can play a significant role to normalize uptake of the vaccine and combat misinformation.

The results of the study revealed that $35 \%$ of the subjects had negative attitude towards COVID-19 vaccine and the findings were statistically significant when compared with working profile of subjects (medical \& dental). More than $40 \%$ of subjects had some concerns regarding unforeseen effects of the vaccine as it is developed during an emergency within a span of few months (fast-track). Similar finding is observed in some other study conducted among health care workers in another country [23].

Results of multivariate analysis showed higher rates of acceptance for vaccination among dental professionals compared to medical professionals. This could be due to higher exposure risks for dentists during oral examination and treatment procedures. However, contrasting findings were reported by some other study conducted on medical and dental students
[11]. Moreover, subjects engaged in COVID-19 duties (dealing with COVID-19 patients) at their respective health care facilities were more willing to get vaccinated as compared to others. Data gathered from a Turkish study conducted on health professionals reported similar findings [10]. This could be due to the fact that subjects dealing with COVID-19 patients have inherent fear of catching the infection which can be passed on to their family.

There is a natural tendency in human beings to gather all information before adopting a new idea that propels us to take a particular decision. It was observed in our study that subjects who were interested in gathering information regarding the COVID-19 vaccine were 2.78 times more willing to get vaccinated as compared to other subjects. Similar findings were observed in a recent study conducted in Democratic Republic of Congo where subjects used to attend lectures and discussions to gather new information regarding vaccine [9]. Subjects who thought that COVID-19 vaccine should be made compulsory for India citizens were more likely to get vaccinated as compared to others. Our findings were in congruence with the findings of another study [18].

Healthcare professional's approval plays a significant part in their patients' vaccination conduct. They can provide significant evidence to the general population and their opinion can be a key factor in patients' judgement to be vaccinated. In this situation and with the moderate positive response for vaccination in our study subjects, there is a substantial need for addressing worries and creating alertness to advance chances for a higher rate of acceptance of the COVID-19 vaccine. The present study has some limitations also. It is not nationally representative as it is conducted in only one state of the country and it is an online survey. Secondly, the study involved a limited sample size as most of the health care professionals were actively engaged in COVID-19220 related duties and therefore had limited time to participate in a survey. Moreover, as the country is witnessing a high surge of COVID-19 cases in the second wave $(300,000$ per day) from the last couple of weeks because of the 'new mutant' strain [22], some subjects who were previously hesitant or unwilling to take the vaccine might consider to opt for the vaccine now (the study was conducted in January 2021). Therefore the actual number of subjects willing to take the vaccine could be somewhat more in the current situation. All these things might have impact on the study's generalisability.

\section{CONCLUSION}

The study concluded that rate of acceptance (willingness) of COVID-19 vaccine among subjects was suboptimal though $65 \%$ of subjects showed 
positive attitude towards the vaccine. Health care workers especially the front line workers are at greater risk of contracting the disease. It is because of this reason that Government of India gave utmost priority to front line workers to get vaccinated. While the expecting COVID-19 vaccine could be effective in protecting the healthcare workers, our data shows that uncertain attributes like safety, development of vaccine in an emergency, unforeseen effects are likely a hurdle for low acceptance.

\section{Recommendations}

Vaccine hesitancy, as a global threat, is affecting all countries. Developing personalised policies to address concerns recognized in the study to decrease vaccine doubtfulness will be crucial to successful widespread vaccination against COVID-19. Interventional educational programs through webinars and seminars should be conducted among health care workers to eliminate fears concerning the vaccine. Health care workers should be made aware of the fact that existing vaccines provide reasonable protection and are effective against many variants (emerging in different nations) of interest and concern. Government can engage eminent personalities and celebrities (spokespersons) to combat any misinformation regarding the vaccine through mass media communication channels. Social media monitoring should be done and any type of erroneous claims regarding COVID vaccine should be refuted. Science has provided us the vaccines, but it is our responsibility to use them to protect ourselves and our world.

\section{Conflict of interest}

The Authors declare no conflict of interest.

\section{REFERENCES}

1. Arda B., Durusoy R., Yamazhan T., Sipahi OR., Taşbakan M., Pullukçu H., Erdem E., Ulusoy S.: Did the pandemic have an impact on influenza vaccination attitude? A survey among health care workers. BMC Infect Dis. 2011;11:87. doi: 10.1186/1471-2334-11-87.

2. Asma S., Akan H., Uysal Y., Poçan AG., Sucakl MH., Yengil E., Gereklioğlu Ç., Korur A., Başhan İ., Erdogan $A F$., Özşahin $A K$., Kut A.: Factors effecting influenza vaccination uptake among health care workers: a multi-center cross-sectional study. BMC Infect Dis. 201;16:192. doi: 10.1186/s12879-016-1528-9.

3. Benefits of getting vaccinated, Center for Disease Control and Prevention (CDC). Available from: www. cdc.gov. Accessed on: $28^{\text {th }}$ April 2021.

4. Black SB., Law B., Chen RT., Dekker CL., Sturkenboom M., Huang WT., Gurwith M., Poland G.: The critical role of background rates of possible adverse events in the assessment of COVID-19 vaccine safety. Vaccine.
2021:S0264-410X(21)00284-X. doi: 10.1016/j. vaccine. 2021.03.016.

5. Cordero DA.: Rebuilding public trust: a clarified response to COVID-19 vaccine hesitancy predicament. J Public Health (Oxf). 2021:fdab020. doi: 10.1093/ pubmed/fdab020.

6. Detoc M., Bruel S., Frappe P., Botelho-Nevers E., Gagneux-Brunon A.: Intention to participate in a COVID-19 vaccine clinical trial and to get vaccinated against COVID-19 in France during the pandemic. medRxiv. 2020;1-14.

7. Faisal HMN., Katti KS., Katti DR.: Differences in Interactions Within Viral Replication Complexes of SARS-CoV-2 (COVID-19) and SARS-CoV Coronaviruses Control RNA Replication Ability. JOM (1989). 2021:1-12. doi: 10.1007/s11837-021-04662-6.

8. Granade CJ., McCord RF., Bhatti AA., Lindley MC.: Availability of Adult Vaccination Services by Provider Type and Setting. Am J Prev Med. 2021;60:692-700. doi: 10.1016/j.amepre.2020.11.013.

9. Kabamba Nzaji M., Kabamba Ngombe L., Ngoie Mwamba G., Banza Ndala DB., Mbidi Miema J., Luhata Lungoyo C., Lora Mwimba B., Cikomola Mwana Bene A., Mukamba Musenga E.: Acceptability of Vaccination Against COVID-19 Among Healthcare Workers in the Democratic Republic of the Congo. Pragmat Obs Res. 2020;11:103-109. doi: 10.2147/POR.S271096.

10. Kaplan AK., Sahin MK., Parildar H., Guvenc IA.. The willingness to accept the COVID-19 vaccine and affecting factors among healthcare professionals: A cross-sectional study in Turkey. Int J Clin Pract. 2021:e14226. doi: 10.1111/ijcp.14226.

11. Kelekar AK., Lucia VC., Afonso NM., Mascarenas AK.: COVID-19 Vaccine Acceptance and Hesitancy Among Dental and Medical Students. J Am Dent Assoc. 2021. doi: 10.1016/j.adaj.2021.03.006

12.Kumar D., Chandra R., Mathur M., Samdariya S., Kapoor N.: Vaccine hesitancy: understanding better to address better. Isr J Health Policy Res. 2016;5:1-8.

13.Larson HJ., Ghinai I.: Lessons from polio eradication. Nature. 2011;473:446-7.

14. Leask J., Kinnersley P., Jackson C., Cheater F., Bedford $H$., Rowles G.: Communicating with parents about vaccination: a framework for health professionals. BMC Pediatr. 2012;12:1. doi:10.1186/1471-2431-12-154

15. Nah EH., Cho S., Park H., Hwang I., Cho HI.: Nationwide seroprevalence of antibodies to SARSCoV-2 in asymptomatic population in South Korea: a cross-sectional study. BMJ Open. 2021;11:e049837. doi: 10.1136/bmjopen-2021-049837.

16. Naz H., Cevik F., Aykın N.: Original Article Influenza Vaccination in Healthcare Workers. 2006.

17. Paterson P., Meurice F., Stanberry LR., Glismann S., Rosenthal SL., Larson HJ.: Vaccine hesitancy and healthcare providers. Vaccine. 2016;34:6700-706. doi: 10.1016/j.vaccine.2016.10.042.

18. Qattan AMN., Alshareef N., Alsharqi O., Al Rahahleh N., Chirwa GC., Al-Hanawi MK.: Acceptability of a COVID-19 Vaccine Among Healthcare Workers in the Kingdom of Saudi Arabia. Front Med (Lausanne). 2021;8:644300. doi: 10.3389/fmed.2021.644300. 
19. Schmitt HJ., Booy R., Aston R., Van Damme P., Schumacher RF., Campins M., Rodrigo C., Heikkinen T., Weil-Olivier C., Finn A., Olcén P., Fedson D., Peltola $H .:$ How to optimise the coverage rate of infant and adult immunisations in Europe. BMC Med. 2007;5:11. doi: 10.1186/1741-7015-5-11.

20.Sharun K., Dhama K.: India's role in COVID-19 vaccine diplomacy. J Travel Med. 2021:taab064. doi: 10.1093/ $\mathrm{jtm} / \mathrm{taab064}$

21. Sim MR.: The COVID-19 Pandemic: Major Risks to Healthcare and Other Workers on the Front Line. 2020:281-2.
22. Triple-mutant 'Bengal strain' a new worry in second wave. Times of India. Available from: www. timesofindia.com. Accessed on: $28^{\text {th }}$ April 2021.

23. Verger P., Scronias D., Dauby N., Adedzi KA., Gobert C., Bergeat M., Gagneur A., Dubé E.: Attitudes of healthcare workers towards COVID-19 vaccination: a survey in France and French-speaking parts of Belgium and Canada, 2020. Euro Surveill. 2021;26:2002047.

24. WHO Coronavirus (COVID-19) Dashboard, World Health Organization. Available from: covid19.who.int. Accessed on 22 $2^{\text {nd }}$ April 2020.

Received: 30.04 .2021

Accepted: 14.05.2021

Published online first: 19.05 .2021 